\title{
RESEARCH
}

\section{Ea Recombinational Hot Spot in the Mouse Major Histocompatibility Complex Maps to the Fourth Intron of the $\mathrm{Ea}$ Gene}

\author{
Shirin Khambata, Jeannie Mody, Amy Modzelewski, Damian Heine, \\ and Howard C. Passmore ${ }^{1}$
}

Department of Biological Sciences and Bureau of Biological Research, Rutgers University, Piscataway, New Jersey 08855-1059

\begin{abstract}
The majority of recombination events detected within the mouse major histocompatibility complex (MHC) fall into regions of limited physical distance known as hot spots of meiotic recombination. The hot spot associated with the Ea gene appears to be active only in the presence of the $p$ allele carried by the intra-MHC recombinant strain B10.F(13R). To study the frequency, regulation, and haplotype specificity of recombination at the $E a$ hot spot, progeny from three different backcrosses involving B1O.F(13R) were screened for recombination events across the MHC using DNA microsatellite markers. Screening of a total of 750 backcross progeny permitted the identification of seven recombinants within the $E a$ gene. Using restriction site polymorphisms, and sequence-based nucleotide polymorphisms, the recombination breakpoints in all seven Ea recombinants were mapped to two adjacent segments of 71 bp and 346 bp in intron 4 of the Ea gene.
\end{abstract}

Homologous recombination plays an important role in eukaryotic organisms by mediating exchange between DNA segments that share extensive sequence homology. In meiosis, it is responsible for the proper segregation of homologous chromosomes and the generation of genetic diversity (Haber 1992; Atcheson and Esposito 1993). Such recombination has often been assumed to occur anywhere along homologous chromosomes and, thus, has traditionally been considered a largely random process. However, limited analysis of this process in eukaryotes shows that some crossing-over occurs preferentially at specific sites in the genome, referred to as recombinational hot spots (Chakravarti et al. 1986; Steinmetz et al. 1986; Atcheson and Esposito 1993).

In mice, recombinational hot spots were discovered during the molecular characterization of the major histocompatibility complex (MHC) when clustering of recombination breakpoints was found in regions of limited physical distance (Steinmetz et al. 1982, 1986; Kobori et al. 1984). The mouse MHC is located on chromosome 17

'Corresponding author.

E-MAll passmore@biology.rutgers.edu; FAX (908) 445-5870. and consists of a cluster of tightly linked genes that encode proteins associated with intercellular recognition and antigen presentation to $\mathrm{T}$ lymphocytes. Studies using restriction fragment length polymorphism (RFLP) and nucleotide sequence analysis have led to the definition of five recombinational hot spots within the $I$ region of the MHC that contains Class II genes. These recombinational hot spots have been found within the $E b$ gene, the $E a$ gene, and the Tap1 gene and near the $L m p 2$ and $P b$ genes (Lafuse and David 1986; Steinmetz et al. 1986; Uematsu et al. 1986; Shiroishi et al. 1990; Yoshino et al. 1994; Zanelli et al. 1995). A striking observation based on the findings of a number of different laboratories, including our own, is that $>\mathbf{9 8 \%}$ of the recombination events that have been detected within a 450$\mathrm{kb}$ segment, spanning the $K$ and the $I$ regions of the MHC, fall within these five well-defined hot spots. The presence or absence of a particular hot spot is in some cases influenced by the genetic composition and the sex of the parental heterozygote in which the recombination event occurs (Lafuse and David 1986; Steinmetz et al. 1986; Shiroishi et al. 1990).

All cases of recombination that have been detected at the $E a$ gene were derived directly or as 
KHAMBATA ET AL.

Table 1. Crosses Involving the $p$ Allele of the Ea Gene from Strain B10.F(13R)

\begin{tabular}{lllll}
\hline Backcross & $\begin{array}{l}\text { Strain combination } \\
\text { (female parent } \times \text { male parent) }\end{array}$ & $\begin{array}{l}\text { Haplotype } \\
\text { combination } \\
\text { at } E a\end{array}$ & $\begin{array}{l}\text { No. of } \\
\text { backcross } \\
\text { animals }\end{array}$ & $\begin{array}{l}\text { No. of } \\
\text { recombinants } \\
\text { at } E \boldsymbol{a}\end{array}$ \\
\hline $\mathrm{H}$ & {$[\mathrm{B} 10 . \mathrm{F}(13 \mathrm{R}) \times \mathrm{B} 10 . \mathrm{S}(9 \mathrm{R})] \mathrm{F}_{1} \times \mathrm{B} 10$} & $p \times k$ & 250 & 1 \\
$\mathrm{~J}$ & $\mathrm{~B} 10 \times[\mathrm{B} 10 . \mathrm{F}(13 \mathrm{R}) \times \mathrm{B} 10 . \mathrm{S}(9 \mathrm{R})] \mathrm{F}_{1}$ & $\begin{array}{l}p \times k \\
p 10 . \mathrm{F}(13 \mathrm{R}) \times \mathrm{A} . \mathrm{TL}] \mathrm{F}_{1} \times \mathrm{B} 10\end{array}$ & 250 & 5 \\
$\mathrm{~K}$ & {$[\mathrm{~B} 10$} & 250 & 1 \\
\hline
\end{tabular}

secondary recombinants from strain B10.F(13R), an intra-MHC recombinant strain that carries the $p$ haplotype at the $E a$ gene (Lafuse and David 1986; Lafuse et al. 1990; Turner et al. 1993). However, the frequency of recombination and the exact location of the crossover sites in the $E a$ hot spot are not known precisely (Lafuse and David 1986; Lafuse et al. 1986). A notable aspect of the $E a$ hot spot is that the $p$ haplotype is one of the few standard inbred strain haplotypes that has never been shown to recombine at the $E b$ hot spot. This has led to the proposition that the $p$ haplotype is deficient in recombination at the $E b$ hot spot and instead has an active $E a$ hot spot (Lafuse and David 1986; Zimmerer and Passmore 1991).

The objectives of this study were to determine the frequency and haplotype specificity of crossing-over within the $\mathrm{Ea}$ hot spot, to determine whether sex and genetic background of the parental heterozygote affect recombination at the $E a$ hot spot and to define precisely the molecular breakpoints associated with the Ea gene.

\section{RESULTS}

\section{Detection of Ea Recombinants}

In this study a total of 750 backcross progeny from crosses $\mathrm{H}, \mathrm{J}$, and $\mathrm{K}$ (Table 1 ) were screened for recombination within the MHC using DNA microsatellite polymorphisms as molecular markers. Crosses $\mathrm{H}$ and $\mathrm{J}$ were designed to study the effect of the sex of the parental heterozygote on recombination at $E a$. Cross $\mathrm{H}$ involved a female parental heterozygote formed from strains $\mathrm{B} 10 . \mathrm{F}(13 \mathrm{R})$ and $\mathrm{B} 10 . \mathrm{S}(\mathrm{9R})$. This combination is known to be permissive for recombination at the $E a$ hot spot (Lafuse and David 1986). Cross J is the reciprocal of cross $\mathrm{H}$, that is, a male parental heterozygote was involved. In all previously detected cases of crossing-over at the $E a$ hot spot, a homozygous B10 background was present (Lafuse and David 1986; Turner et al. 1993). To determine whether a homozygous B10 background is necessary for $E a$ recombinational activity, cross $\mathrm{H}$ was designed using only a B10 background, whereas cross $\mathrm{K}$ was designed using a B10 and $\mathrm{A}$ background combination.

Out of a total of 750 backcross progeny, 7 animals were found to carry a recombination in a $2.2-\mathrm{kb}$ interval between the D17Rua10 microsatellite in exon 5 of the Ea gene and the D17Rua2 microsatellite in intron 2 of the Ea gene (Table 1; Fig. 1). Thus, the crossover breakpoint sites of all seven $E a$ recombinants lie within the $E a$ gene. The frequency of recombination at the $E a$ hot spot ranges between 1 out of 50 and 1 out of 250 in the three crosses analyzed.

In crosses $\mathrm{H}$ and $\mathrm{J}$, all recombination within the $K$ and $I$ regions (a segment of $\sim 450 \mathrm{~kb}$ ) was confined to the $E a$ gene. In cross $\mathrm{K}$, four additional $I$ region recombinants were identified outside of the $E a$ gene. The precise location of these four recombinants is currently under investigation.

\section{Localization of Crossover Sites}

Analysis of DNA microsatellite polymorphisms places the seven $E a$ recombinants in a $2.2-\mathrm{kb}$ segment between the D17Rua10 and the D17Rua2 microsatellites within the $E a$ gene. In an attempt to localize the crossover sites within this $2.2-\mathrm{kb}$ segment, three polymorphic restriction sites that were present in the $k$ allele but absent in the $p$ allele were used as molecular markers (Table 2). The recombinants J84 and J174 were found to crossover in a 167-bp segment between the NspI site in exon 5 and the BanII site in intron 4 . The recombinants $\mathrm{H} 179, \mathrm{~J} 5, \mathrm{~J} 17, \mathrm{~J} 214$, and $\mathrm{K} 119$ were found to have crossover breakpoints between the BanII site in intron 4 and the D17Rua2 microsatellite in intron 2. 


\section{EA RECOMBINATIONAL HOT SPOT}

\section{Ea gene}

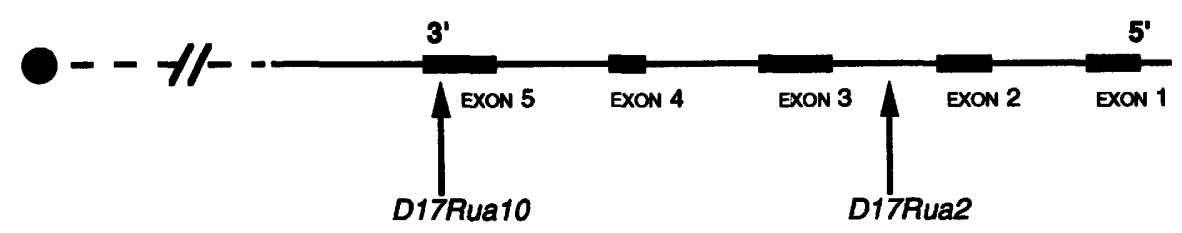

$\longmapsto 2.2 \mathrm{~kb} \longrightarrow$

Figure 1 Structure of the Ea gene showing the 2.2-kb recombination interval in seven recombinant animals. The $E a$ gene has five exons separated by four introns and is $\sim 3.6 \mathrm{~kb}$ in length (Mathis et al. 1983). Broken lines indicate regions of unknown length and sequence. $(\uparrow)$ D17Rua10 and D17Rua2, the two polymorphic microsatellite markers between which the Ea recombinants have been found to cross over.

\section{Identification of Precise Breakpoint Regions}

Knowledge of sequence-based nucleotide polymorphisms between the parental alleles $p$ and $k$ was essential for mapping the recombination breakpoints precisely in each of the seven $E a$ recombinants. Upon sequencing a 644-bp segment encompassing part of exon 5 and most of intron 4 , four polymorphic nucleotide sites were detected between the $p$ and the $k$ alleles (Fig. 2) and three polymorphic nucleotide sites were detected between the $b$ and the $k$ alleles. These polymorphic sites were used as molecular markers for sequence analysis. The recombinants J84 and J174 were found to have a 71-bp breakpoint region in intron 4 , between a sequence-based polymorphic site at position 2724 and a BanII polymorphic site at position 2653 (Fig. 2). The recombinants $\mathrm{H} 179, \mathrm{~J} 5, \mathrm{~J} 17, \mathrm{~J} 214$, and $\mathrm{K} 119$ were found to have a 346-bp breakpoint region in intron 4, between a BanII polymorphic site at position 2653 and a sequence-based polymorphic site at position 2307 (Fig. 2). The sequence analysis of the 644-bp fragment containing intron 4 revealed that two additional inbred strains carrying the $p$ haplotype, strains $\mathrm{P} / \mathrm{J}$ and $\mathrm{C} 3 \mathrm{H} . \mathrm{NB}$, are identical in nucleotide sequence to the $p$ haplotype carried by B10.F(13R).

\section{DISCUSSION}

The hot spot of meiotic recombination associated with the $E a$ gene of the mouse MHC has been defined previously by eight cases of recombination between the $p$ and $k$ haplotypes (Lafuse and
David 1986; Turner et al. 1993) and two cases of recombination between the $p$ and $f$ haplotypes (Lafuse et al. 1990). The $10 \mathrm{Ea}$ recombinants were derived either directly or as secondary recombinants from crosses involving the intraMHC recombinant strain B10.F(13R), which carries the $p$ allele at the $E a$ gene. It is important to note that intra-Ea recombination has never been reported in crosses that do not involve the $p$ allele. Thus, the $p$ allele appears to act in a dominant manner to permit recombination at the $E a$ hot spot (Lafuse and David 1986; Zimmerer and Passmore 1991). The precise frequency of crossing-over associated with the Ea hot spot and the exact location of the breakpoint sites in the $E a$ recombinants were not determined (Lafuse and David 1986; Lafuse et al. 1986).

In an effort to study the frequency, regulation, and haplotype specificity of recombination at the $E a$ hot spot, progeny from three backcrosses have been examined for intra-MHC recombination (crossing-over). A total of 750 progeny from three backcrosses involving the $p$ haplotype at the $E a$ gene from strain B10.F(13R) and the $k$ haplotype at the $E a$ gene from strains B10.S(9R) or A.TL were screened for recombination across the MHC. Among a total of 11 intra-I region recombinants, 7 were found to crossover within the $E a$ gene. The frequency of crossingover at the $E a$ hot spot in the three crosses varied between 1 out of 50 and 1 out of 250 . The recombination rates within the Ea gene appear to differ between females and males (crosses $\mathrm{H}$ and J), although the numbers involved are too small to be able to determine whether the difference is significant. However, it is clear that recombination at the $E a$ hot spot can occur in both sexes. In addition, a homozygous B10 background does not seem to be absolutely necessary for recombination to take place at $E a$, because an $E a$ recombinant was detected in the $K$ cross that carries a mixed genetic background.

The seven $E a$ recombinants identified in the present study have been mapped precisely to two adjacent, nonoverlapping segments of $71 \mathrm{bp}$ and 
KHAMBATA ET AL.

Table 2. Crossover Segments of Ea Recombinants

\begin{tabular}{|c|c|c|c|c|c|}
\hline \multirow[b]{2}{*}{$\begin{array}{l}\text { Backcross } \\
\text { animal }\end{array}$} & \multicolumn{5}{|c|}{ Genetic markers and location (listed $3^{\prime} \rightarrow 5^{\prime}$ ) } \\
\hline & $\begin{array}{l}\text { exon } 5 \\
\text { Rua } 10\end{array}$ & $\begin{array}{l}\text { exon } 5 \\
\text { Tth } 1111 \\
2829\end{array}$ & $\begin{array}{l}\text { exon } 5 \\
\text { Nspl } \\
2821\end{array}$ & $\begin{array}{l}\text { intron } 4 \\
\text { Banll } \\
2653\end{array}$ & $\begin{array}{l}\text { intron } 2 \\
\text { Rua2 }\end{array}$ \\
\hline H179 & $p$ & $p$ & $p$ & $p----$ & $k$ \\
\hline 15 & $p$ & $p$ & $p$ & $p----$ & $k$ \\
\hline$j 17$ & $p$ & $p$ & $p$ & $p----$ & $k$ \\
\hline j214 & $p$ & $p$ & $p$ & $p----$ & $k$ \\
\hline K119 & $p$ & $p$ & $p$ & $p----$ & $k$ \\
\hline J84 & $k$ & $k$ & $k---$ & $p$ & $p$ \\
\hline J174 & $p$ & $p$ & $p---$ & $k$ & $k$ \\
\hline
\end{tabular}

(-- ) Region in which crossover occurred.

Nucleotide numbering is based on Mathis et al. (1983).

$346 \mathrm{bp}$ in intron 4 of the $E a$ gene. Because meiotic recombination is a complicated phenomenon that perhaps results in a transient heteroduplex DNA formation, the two recombination segments might represent different manifestations of a single site of enhanced recombination. Multiple, nonoverlapping breakpoint regions have also been observed in the $E b$ and the Lmp2 hot spots, which are the two other well-characterized I region hot spots (Shiroishi et al. 1991; Bryda et al. 1992). In all seven $E a$ recombinants reported in this study, the sequence of the region that contains the recombination breakpoint was identical to the parental sequence, indicating that meiotic recombination is very precise and is not accompanied by the loss or gain of nucleotides at the site of exchange. This remarkable fidelity of sequence conservation during recombination makes it impossible to pinpoint the exact nucleotides at which recombination was initiated or resolved. This observation is consistent with previous studies involving recombinants at the $E b$ and $L m p 2$ hot spots (Shiroishi et al. 1991; Zimmerer and Passmore 1991; Sant'Angelo et al. 1992).

Very little is known about the mechanism or the possible signals regulating site-restricted meiotic recombination within MHC hot spots or any other similar sites in higher eukaryotes. The $E a$ gene ( $3.6 \mathrm{~kb}$ in length) that contains the $E a$ hot spot was screened for potential recombination signal sequences using MacVector sequence analysis software. Nucleotide sequences that have been implicated in the recombination process at the $E b$ and the Lmp2 hot spots (Shenkar et al. 1991; for review, see Shiroishi et al. 1993) were not found to be contained in the $E a$ gene.

All 7 cases of recombination at the $E a$ hot spot (including the 7 detected in this study) were derived directly or as secondary recombinants from strain B10.F(13R), an intra-MHC recombinant strain in which the $E a$ gene and adjoining sequences are derived from the $p$ haplotype. Therefore, it was surprising that in a previous study by Heine et al. (1994), not a single case of recombination at the $E a$ hot spot was detected in 1093 progeny from four backcrosses, each of which involved the $p$ haplotype of the MHC from strains $\mathrm{P} / \mathrm{J}$ or C3H.NB. Although the $p$ haplotypes present in B10.F(13R), $\mathrm{P} / \mathrm{J}$, and C3H.NB are of a different recent lineage, they appear to be serologically indistinguishable (Klein 1989). One possible explanation for the differences in specificity of recombination at $E a$ is that the $p$ haplotype of strain B10.F (13R) has genetically diverged from the $p$ haplotype of strains $\mathrm{P} / \mathrm{J}$ and C3H.NB at the $E a$ hot spot. In an attempt to examine this possibility, DNA from strains B10.F(13R), P/J, and C3H.NB was sequenced across a 644-bp region containing the $E a$ hot spot. The sequences from the three strains were found to be identical in the region examined. This rules out the possibility that the $p$ haplotype of strain B10.F(13R) is permissive for recombination at the $E a$ hot spot because it has genetically diverged from the $p$ haplotype of strains P/J and C3H.NB at the $E a$ hot spot. Further sequence analysis could help determine whether the $p$ haplotype from B10.F $(13 R)$ is divergent from the $p$ haplotype of $\mathrm{P} / \mathrm{J}$ and C3H.NB in a region outside of the hot spot itself. 
EA RECOMBINATIONAL HOT SPOT

\section{exon 5}

intron 4

exon 4

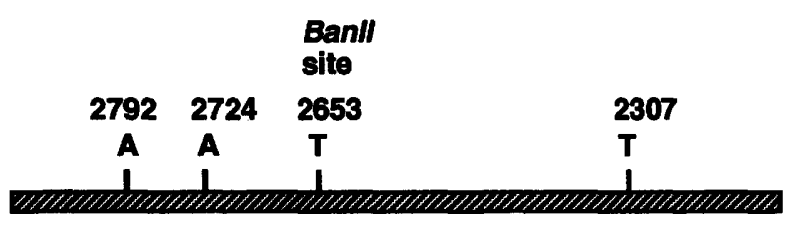

\section{kallele}

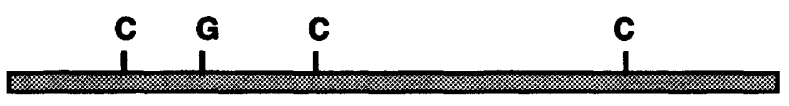

$J 84(k / p)$

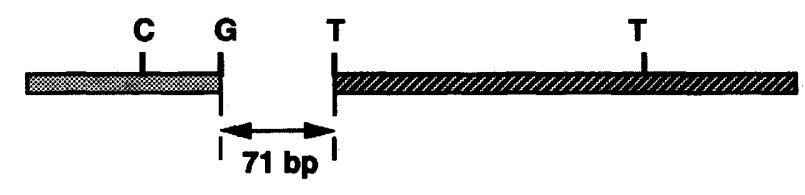

$J 174(p / k)$
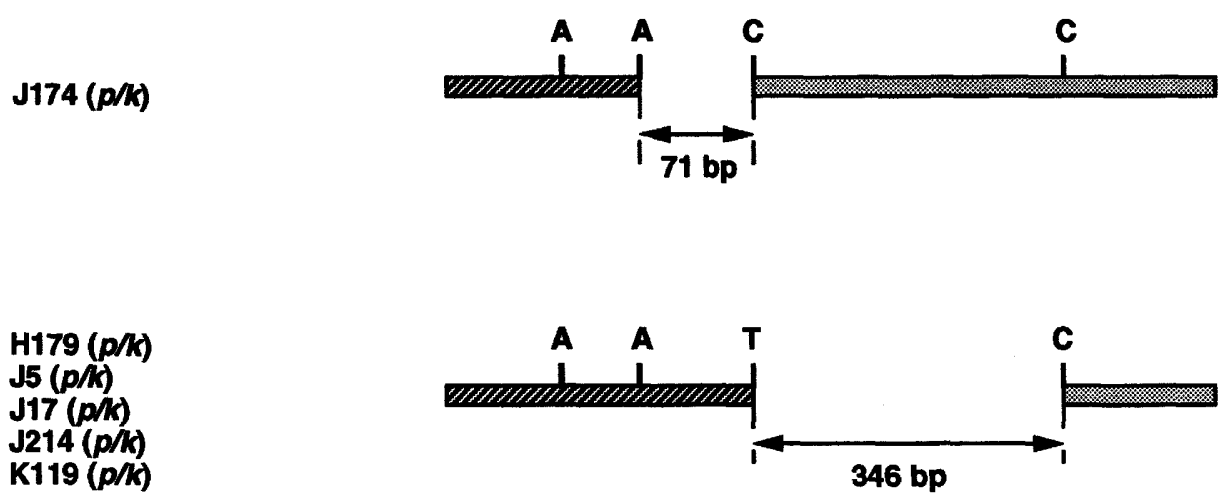

Figure 2 Map of the 3' end of the Ea gene showing crossover sites for seven intra-Ea recombinants derived from the $p$ and the $k$ alleles. Positions of the nucleotide polymorphisms which distinguish between the $p$ and the $k$ haplotypes are indicated by short vertical lines.

\section{METHODS}

\section{Animals}

The crosses used in this study are listed in Table 1 and are referred to as crosses $\mathrm{H}, \mathrm{J}$, and $\mathrm{K}$. The intra-MHC recombinant strains B10.F(13R) and B10.S(9R) were obtained from the McLaughlin Research Institute (Great Falls, MT). The intra-MHC recombinant strain A.TL and the inbred strain C57BL/10J (synonym B10) were obtained from The Jackson Laboratory (Bar Harbor, ME). All $\mathrm{F}_{1}$ crosses and backcrosses were performed at Rutgers University. DNA was prepared from liver tissue using a modification of the high-salt extraction technique (Miller et al. 1988).

\section{DNA Microsatellite Polymorphisms}

Genetic mapping was performed using DNA markers that could be typed by the polymerase chain reaction (PCR). To identify recombinants, DNA samples from backcross prog- eny were screened using microsatellites (simple sequence repeats) that are polymorphic between the two parental strains. Initial screening for recombinants was carried out using D17Mit81 and D17Mit47 microsatellite markers (Dietrich et al. 1992) that are centromeric and telomeric to the MHC, respectively. These were considered outside markers. For the K cross progeny, the D17Mit63 genetic marker (Dietrich et al. 1992) was used instead of D17Mit81 because it gave a more clear polymorphism between the parental alleles. All backcross progeny were also genotyped using a DNA microsatellite primer pair from within the MHC. Only recombinant animals defined by crossovers between the outside markers were characterized for additional, intervening genetic markers. Those animals that carried a recombination between D17Mit28 $(H-2 K)$ and D17Nds3 (Tnfb) (Dietrich et al. 1992) were defined as MHC recombinants. The MHC recombinants that carried a recombination between $D 17 R u a 10$, a microsatellite in exon 5 of the $E a$ gene, and D17Rua2, a microsatellite in the second intron of the $E a$ gene (Heine et al. 1994), were 


\section{KHAMBAIA ET AL.}

considered as $E a$ recombinants (Fig. 1). The D17Rua10 primers (10F, 5'-CAGCATTAAGCCTCAAGAAT-3' and 10R, 5'-GTCACAACCCAAGGTGTTTA-3') were designed for this study, to amplify a 245-bp segment containing a poly(T) mononucleotide repeat in the 3 '-untranslated region of exon 5 in the $E a$ gene. This primer pair was designed from the DNA sequence of the $k$ allele of $\mathrm{H2}-\mathrm{Ea}$ described previously in Mathis et al. (1983).

The PCR primers for DNA microsatellites (Map Pairs), based on Dietrich et al. (1992), were obtained from Research Genetics Inc. (Huntsville, AL). The Rua primers were custom-made at Biosynthesis Inc. (Lewisville, TX). The products of the PCR reactions were resolved on 8\%$10 \%$ nondenaturing acrylamide gels and visualized by ethidium bromide staining.

\section{Restriction Site Polymorphisms}

The localization of crossover sites within the $E a$ gene was done using PCR amplification and analysis of restriction site polymorphisms between the parental alleles. The D17Rua19 primers (19F, 5'-AATGTTGTAGAACGCCGACA-3' and 19R, 5'-CTTAAAACCCTAGTGAGGCT-3') were designed from the sequence of the $\mathrm{H} 2-\mathrm{Ea}$ gene (Mathis et al. 1983) to amplify a 1158-bp segment (from position 2116 to position 3273) encompassing intron 4 and exon 5. PCR amplifications were performed on DNA from the parental strains B10.F(13R) that carries the $p$ haplotype at the $E a$ gene, B10.S(9R) and A.TL that carry the $k$ haplotype at the $E a$ gene, and B10, the strain to which the backcrosses were made. The resulting products were then single digested with a panel of 18 different restriction enzymes. The products of the digestions were resolved on a $1 \%$ Synergel-agarose gel (Diversified Biotech, Newton Centre, MA). The gels were visualized by ethidium bromide staining. Of the 18 restriction enzymes used, 6 revealed polymorphisms between the parental alleles $p$ and $k$.

The 1158-bp segment containing intron 4 and exon 5 was then amplified in each of the $E a$ recombinants. The resulting PCR products were single digested with three of the six restriction enzymes that had a polymorphic site between $p$ and $k$. The three restriction enzymes used were Tth111I that has a polymorphic site at position 2829 in exon 5, NspI that has a polymorphic site at position 2821 in exon 5, and BanII that has a polymorphic site at position 2653 in intron 4 (Table 2). For all three restriction enzymes, the site was present in the $k$ allele and absent in the $p$ allele. The resulting products were resolved on a $1 \%$ Synergel-agarose gel and visualized by ethidium bromide staining to determine whether the recombinants were $p$ like or $k$-like at each polymorphic restriction site.

\section{Sequence-based Nucleotide Polymorphisms}

Mapping of recombination breakpoints in the $E a$ recombinants required the detection of sequence-based nucleotide polymorphisms unique to the parental alleles involved in each recombination event. For this purpose, our strategy was to sequence the $p, k$, and $b$ parental alleles involved in crosses $\mathrm{H}, \mathrm{J}$, and $\mathrm{K}$, starting from position 2800 in exon 5 at the $3^{\prime}$ end of the $E a$ gene and moving toward the $5^{\prime}$ end of the $E a$ gene. The $b$ allele was sequenced only to help clarify any confusion that might arise from the presence of more than one band at the same position on a sequencing gel. Overlapping sections of exon 5 and intron 4 were amplified by PCR. The resulting PCR products were then purified from $1 \%$ agarose gels using the Geneclean Spin Kit (Bio 101, Vista, CA). The purified PCR fragments were then sequenced using the Sequenase Version 2.0 DNA Polymerase PCR Product Sequencing Kit (U.S. Biochemical, Cleveland, OH). After four polymorphic sites between the $p$ allele and the $k$ allele were detected in a 644-bp segment, the DNA of each $E a$ recombinant was sequenced across intron 4 in exactly the same manner as the parental DNA. Computer sequence analysis was performed using MacVector sequence analysis software for Macintosh (IBI, New Haven, CT).

\section{PCR Conditions}

All PCR reactions were performed on an Omnigene temperature cycler (Hybaid, Middlesex, UK) in $10 \mathrm{~mm}$ Tris-HCl (pH 9.0), $50 \mathrm{~mm} \mathrm{KCl}, 1.5 \mathrm{~mm} \mathrm{MgCl}_{2}, 0.1 \%$ Triton X-100, $200 \mu \mathrm{M}$ of each dNTP, $0.5 \mu \mathrm{M}$ of each primer, and 1.25 units of Taq DNA polymerase. Map Pair microsatellites (Research Genetics) were amplified in a total reaction volume of $25 \mu \mathrm{l}$, with a $25-\mu \mathrm{l}$ mineral oil overlay using a tube control program. Conditions were a predenaturation step at $95^{\circ} \mathrm{C}$ for $2.5 \mathrm{~min}$, followed by 45 cycles of denaturation at $94^{\circ} \mathrm{C}$ for $1 \mathrm{~min}$, annealing at $55^{\circ} \mathrm{C}$ for $1.5 \mathrm{~min}$, and elongation at $72^{\circ} \mathrm{C}$ for $1.5 \mathrm{~min}$, followed by a final extension step at $72^{\circ} \mathrm{C}$ for $10 \mathrm{~min}$. D17Rua2 and D17Rua10 were amplified under the same conditions but with an annealing temperature of $57^{\circ} \mathrm{C}$. Amplification using D17Rua19 primers was achieved in a 50- $\mu$ l total volume, with a $50-\mu l$ mineral oil overlay using a tube control program. Conditions were a predenaturation step at $95^{\circ} \mathrm{C}$ for $2.5 \mathrm{~min}$, followed by 45 cycles of $94^{\circ} \mathrm{C}$ for $1 \mathrm{~min}, 58^{\circ} \mathrm{C}$ for $2 \mathrm{~min}$, and $72^{\circ} \mathrm{C}$ for $3 \mathrm{~min}$, followed by a final extension step at $72^{\circ} \mathrm{C}$ for $10 \mathrm{~min}$.

\section{ACKNOWLEDGMENTS}

This work was funded by grant GM 46641 from the National Institutes of Health. S.K. was supported by The Anne B. and James H. Leathem Scholarship Fund and The Nicholas C. Palczuk Research Fund.

The publication costs of this article were defrayed in part by payment of page charges. This article must therefore be hereby marked "advertisement" in accordance with 18 USC section 1734 solely to indicate this fact.

\section{REFERENCES}

Atcheson, C.L. and R.E. Esposito. 1993. Meiotic recombination in yeast. Curr. Opin. Genet. Dev. 3: 736-744.

Bryda, E.C., J.A. DePari, D.B. Sant'Angelo, D.B. Murphy, and H.C. Passmore. 1992. Multiple sites of crossing over within the $E b$ recombinational hotspot in the mouse. Mammalian Genome 2: 123-129.

Chakravarti, A., S.C. Elbein, and M.A. Permutt. 1986. Evidence for increased recombination near the human 


\section{EA RECOMBINATIONAL HOT SPOI}

insulin gene: Implication for disease association studies. Proc. Natl. Acad. Sci. 83: 1045-1049.

Dietrich, W., H. Katz, S.E. Lincoln, H.S. Shin, J. Friedman, N.C. Dracopoli, and E.S. Lander. 1992. A genetic map of the mouse suitable for typing interspecific crosses. Genetics 131: 423-447. (Supplemented by additional markers in Whitehead Institute/MIT Center for Genome Research, Genetic Map of the Mouse, January 1995 Database Release.)

Haber, J.E. 1992. Exploring the pathways of homologous recombination. Curr. Opin. Cell Biol. 4: 401-412.

Heine, D., S. Khambata, K.S. Wydner, and H.C. Passmore. 1994. Analysis of recombinational hotspots associated with the $p$ haplotype of the mouse MHC. Genomics 23: 168-177.

Klein, J. 1989. Congenic and segregating inbred strains. In Genetic variants and strains of the laboratory mouse (ed. M. Lyon and A. Searle), pp. 797-825. Oxford University Press, New York, NY.

Kobori, J.A., A. Winto, J. Mc.Nicholas, and L. Hood. 1984. Molecular characterization of the recombinant region of six murine major histocompatibility complex (MHC) I region recombinants. J. Mol. Cell Immunol. 1: 125-131.

Lafuse, W.P. and C.S. David. 1986. Recombination hotspots within the $I$ region of the mouse $H$ - 2 complex map to the $E b$ and $E a$ genes. Immunogenetics

24: $352-360$.

Lafuse, W.P., N. Berg, S. Savarirayan, and C.S. David. 1986. Mapping of a second recombination hotspot within the I-E region of the mouse $\mathrm{H}-2$ complex. J. Exp. Med. 163: 1518-1528.

Lafuse, W.P., S.T. Lee, and C.S. David. 1990. Molecular analysis of two recombinant strains with crossovers in the $E a$ recombination hotspot. J. Immunogenet. 17: 169-176.

Mathis, D.J., C.O. Benoist, V.E. Williams II, M.R. Kanter, and H.O. McDevitt. 1983. The murine E- alpha immune response gene. Cell 32: 745-754.

Miller, S.A., D.D. Dykes, and H.F. Polesky. 1988. A simple salting out procedure for extracting DNA from human nucleated cells. Nucleic Acids Res. 16: 1215.

Sant'Angelo, D.B., W.P. Lafuse, and H.C. Passmore. 1992. Evidence that nucleotide sequence identity is a requirement for meiotic crossing over within the mouse $E b$ recombinational hotspot. Genomics 13: 1334-1336.

Shenkar, R., M. Shen, and N. Arnheim. 1991. DNAse I-hypersensitive sites and transcription factor-binding motifs within the mouse $E b$ meiotic recombination hotspot. Mol. Cell. Biol. 11: 1813-1819.

Shiroishi, T., N. Hanzawa, T. Sagai, M. Ishiura, T. Gojobori, M. Steinmetz, and K. Moriwaki. 1990.
Recombinational hotspot specific to female meiosis in the mouse major histocompatibility complex. Immunogenetics 31: 79-88.

Shiroishi, T., T. Sagai, N. Hanzawa, H. Gotoh, and K. Moriwaki. 1991. Genetic control of sex-dependent meiotic recombination in the major histocompatibility complex of the mouse. EMBO I. 10: 681-686.

Shiroishi, T., T. Sagai, and K. Moriwaki. 1993. Hotspots of meiotic recombination in the mouse major histocompatibility complex. Genetica 88: 187-196.

Steinmetz, M., K. Minard, S. Horvath, J. McNicholas, J. Frelinger, C. Wake, E. Long, B. Mach, and L. Hood. 1982. A molecular map of the immune response region from the major histocompatibility complex of the mouse. Nature 300: $35-42$.

Steinmetz, M., D. Stephan, and K. Fischer Lindahl. 1986. Gene organization and recombination hotspots in the murine major histocompatibility complex. Cell 44: 895-904.

Turner, S.K., C.L. Miller, P.J. Wettstein, K.J. Hasenkrug, J.H. Stimpfling, and G.A. Carlson. 1993. Meiotic recombination within the $H 2 K-H 2 D$ interval: Characterization of a panel of congenic mice, including 12 new strains, using DNA markers. Immunogenetics 38: $322-340$.

Uematsu, Y., H. Kiefer, R. Schulze, K. Fischer Lindahl, and M. Steinmetz. 1986. Molecular characterization of a meiotic recombinational hotspot enhancing homologous equal crossing-over. EMBO J. 5: 2123-2129.

Yoshino, M., T. Sagai, K. Fischer Lindahl, Y. Toyoda, T. Shiroishi, and K. Moriwaki. 1994. No dosage effect of recombinational hotspots in the mouse major histocompatibility complex. Immunogenetics 39: 381-389.

Zanelli, E., P. Zhou, H. Cao, M.K. Smart, and C.S. David. 1995. Genetic polymorphism of the mouse major histocompatibility complex-associated proteasome subunit Lmp7. Immunogenetics 41: 251-254.

Zimmerer, E.J. and H.C. Passmore. 1991. Structural and genetic properties of the $E b$ recombinational hotspot in the mouse. Immunogenetics 33: 132-140.

Received November 2, 1995; accepted in revised form February 6, 1996. 


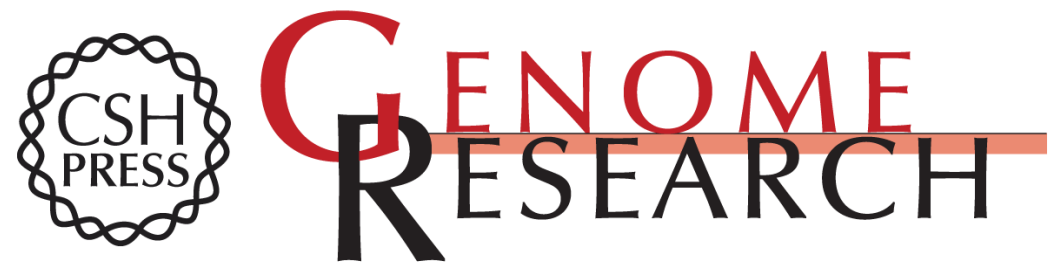

\section{Ea recombinational hot spot in the mouse major histocompatibility complex maps to the fourth intron of the Ea gene.}

S Khambata, J Mody, A Modzelewski, et al.

Genome Res. 1996 6: 195-201

Access the most recent version at doi:10.1101/gr.6.3.195

References This article cites 24 articles, 4 of which can be accessed free at:

http://genome.cshlp.org/content/6/3/195.full.html\#ref-list-1

\section{License}

Email Alerting Receive free email alerts when new articles cite this article - sign up in the box at the Service top right corner of the article or click here.

\section{Affordable, Accurate Sequencing.}

To subscribe to Genome Research go to:

https://genome.cshlp.org/subscriptions 